\title{
Dehydration kinetics of Portland cement paste at high temperature
}

\author{
Qi Zhang · Guang Ye
}

CEEC-TAC1 Conference Special Issue

(C) The Author(s) 2012. This article is published with open access at Springerlink.com

\begin{abstract}
Portland cement paste is a multiphase compound mainly consisting of calcium-silicate-hydrate (CSH) gel, calcium hydroxide $(\mathrm{CH})$ crystal, and unhydrated cement core. When cement paste is exposed to high temperature, the dehydration of cement paste leads to not only the decline in strength, but also the increased pore pressure in the paste. In this article, the dehydration kinetic was characterized in term of the combination of kinetics of $\mathrm{CSH}$ and $\mathrm{CH}$. The dehydration kinetics data of cement paste at different heating rates was collected by thermogravimetry. The influence of temperature on the reaction rate is analyzed by Arrhenius equation. The Arrhenius parameters of $\mathrm{CSH}$ and $\mathrm{CH}$, activation energy, and preexponential factor are determined by isoconversional method. The calculated kinetics parameters were validated by further experimental data finally.
\end{abstract}

Keywords Kinetics - Dehydration - Cement paste . High temperature $\cdot \mathrm{TG} \cdot$ Isoconversional method

\section{Introduction}

The dehydration of Portland cement paste plays an important role in the concrete structure explosive spalling at fire. Calcium silicate hydrate $(\mathrm{CSH})$ and calcium hydroxide $(\mathrm{CH})$ are the main hydration phases which dominate the properties of Portland cement paste. The temperature range corresponds to the dehydration of $\mathrm{CSH}$ is about from 105 to $1,000^{\circ} \mathrm{C}$ [1]. The temperature range corresponds to the dehydration of $\mathrm{CH}$ is about from 400 to

Q. Zhang $(\bowtie) \cdot$ G. Ye

Stevinweg 1, 2628 CN Delft, The Netherlands

e-mail: zhangqi731@gmail.com $550^{\circ} \mathrm{C}$. The dehydration of cement paste, together with evaporation of capillary water, has a great influence on the build-up of high pore pressure, which can result to explosive spalling of concrete.

The dehydration analysis of cement paste can be facilitated by the use of thermal analysis techniques, including thermogravimetric analysis (TG) and differential scanning calorimetry (DSC). The dehydrations of different cement pastes [1-4] were investigated by $\mathrm{TG}$ at given heating rates. The chemical meanings of peaks of TG/DTG curve were qualitatively described [2-4]. The dehydration kinetics of cemetitious materials were usually characterized by the modified Arrhenius equation [5], where the cemetitious materials were considered as pure substance.

However, the dehydration kinetics of Portland cement paste is too complex to be described by a single Arrhenius equation. The dehydration of Portland cement paste is comprised by dehydration of $\mathrm{CSH}$ and $\mathrm{CH}$ [4]. Moreover, the dehydration of CSH itself is a multi-step reaction [6,7], in which the Arrhenius parameters (activation energy and pre-exponential factor) vary with dehydration degree. Therefore, it's difficult to use a single pair of Arrhenius parameters to reveal the chemical mechanism and to predict the dehydration process of cement paste accurately.

In this study, the dehydration kinetics of Portland cement paste was characterized as the combination of two parallel kinetics processes, i.e., kinetics of $\mathrm{CSH}$ and $\mathrm{CH}$. To confirm that these two reactions dominate the dehydration process, the crystalline composition of cement paste sample was characterized by X-ray diffraction. The dehydration mass losses (TG curves) of cement paste at different heating rates were collected by thermogravimetry for the parameters determination. The TG curves of cement paste were separated into the TG curves of $\mathrm{CSH}$ and $\mathrm{CH}$ by a graphic method. The dehydration kinetics parameters of 
$\mathrm{CH}$ and $\mathrm{CSH}$ were computed, respectively, based on the TG data. The isoconvertional method [8] was performed to calculate the reaction-degree-dependent activation energy of $\mathrm{CSH}$ and $\mathrm{CH}$. This kinetics model and calculated parameters were verified by further experimental data.

\section{Material}

The experiment were carried out by using an ordinary Portland cement (OPC) CEM I 42.5N. The water/cement ratio was 0.5 . The cement paste was cast in small plastic bottles. After curing in closed bottles for 28 days, the hardened paste were removed from the plastic bottles. Before measurement, the cement paste samples were stored in the oven at $105^{\circ} \mathrm{C}$ for $24 \mathrm{~h}$ to remove the free water. The cement paste samples were milled into powders $(<50 \mu \mathrm{m})$ for thermogrametic analysis.

\section{Method}

Because the cement paste with age of 28 days was investigated in this study, the possible carbonation in samples is assumed to be negligible. The dehydration process of Portland cement paste is considered as the reactions as following:

$$
\begin{aligned}
& (\mathrm{CaO})_{\mathrm{a}} \mathrm{SiO}_{2}\left(\mathrm{H}_{2} \mathrm{O}\right)_{\mathrm{b}} \rightleftharpoons(\mathrm{CaO})_{\mathrm{a}} \mathrm{SiO}_{2}\left(\mathrm{H}_{2} \mathrm{O}\right)_{\mathrm{b}-\mathrm{c}} \\
& \quad+c \cdot \mathrm{H}_{2} \mathrm{O}^{\text {vapor }} \\
& \mathrm{Ca}(\mathrm{OH})_{2} \rightleftharpoons \mathrm{CaO}+\mathrm{H}_{2} \mathrm{O}^{\text {vapor }}
\end{aligned}
$$

the Friedman model [9] was used for kinetics of nth-order reaction in this study.

$f(\alpha)=(1-\alpha)^{n}$

where $n$ is the reaction order, $\alpha$ is the reaction degree. Arrhenius equation is used to describe the influence of temperature.

$K(T)=A_{0} \exp -E_{\mathrm{a}} / R T$

where $A_{0}$, the pre-exponential factor and $E_{\mathrm{a}}$, the activation energy are referred to as the Arrhenius parameters. Given attention to the reaction order and temperature, the kinetics of dehydration of each phase can generally be expressed as following equation:

$\frac{\mathrm{d} \alpha}{\mathrm{d} t}=K(T) f(\alpha)$

Equation 5 characterizes the dehydration kinetics of $\mathrm{CSH}$ and $\mathrm{CH}$. Hence, the global dehydration kinetics of cement paste is considered as the combination of the dehydration kinetics of $\mathrm{CSH}$ and $\mathrm{CH}$. The kinetics analysis of $\mathrm{CSH}$ and $\mathrm{CH}$ is carried out by following four steps:
Crystalline phase identification

Portland cement paste is a complex material that might contain some minor hydration products and calcium carbonate $\left(\mathrm{CaCO}_{3}\right)$. These minor phases can effect the total mass loss of cement paste at high temperature. Therefore, before thermal analysis, the crystalline composition of cement paste must be identified to make sure that the minor phases are negligible in samples, and that dehydration of $\mathrm{CSH}$ and $\mathrm{CH}$ is the main reaction during heating. The mineral composition of cement paste sample was measured by powder X-ray diffraction (XRD). The X-ray source of $\mathrm{Cu} \mathrm{K} \alpha$ radiation $(\lambda=1.54056 \AA)$ was used. The scan step size was $0.02^{\circ}$ in the range $2 \theta$ from $5^{\circ}$ to $70^{\circ}$.

Mass loss data collection by thermogravimetric analysis

The simultaneous thermogravimetry analyzer was used to measure the TG curves. The purge gas was nitrogen, and the gas velocity was $20 \mathrm{ml} / \mathrm{min}$. The sample was heated from 30 to $1,100^{\circ} \mathrm{C}$ with different rates: $1,2,5,10$ and $30^{\circ} \mathrm{C} / \mathrm{min}$.

\section{Separation of TG curve}

To study the dehydration kinetics of hydrates separately, the TG curves of cement paste are divided into TG curves due to dehydration of $\mathrm{CSH}$ and $\mathrm{CH}$ respectively. As Fig. 1 shown, the derivative of mass loss (DTG) has a large peak at around $450^{\circ} \mathrm{C}$, which stands for the dehydration of $\mathrm{CH}$. The onset and offset point of dehydration of $\mathrm{CH}$ can be determined by the edge of that peak. The mass loss at this segment between the onset and offset is contributed by both the dehydration of $\mathrm{CH}$ and $\mathrm{CSH}$. It is assumed that the rate of dehydration of $\mathrm{CSH}$ in this segment was the same with the neighbored segments in this study. Therefore, two tangent lines are made through onset and offset, which stand for the mass loss of CSH. The mass loss due to dehydration of $\mathrm{CH}$ can be known by calculating the vertical distance of these two trend lines at the midpoint between onset and offset (Fig. 1). By this graphic method, the TG curve of cement paste is separated into TG curves of CSH and $\mathrm{CH}$ in Fig. 1.

Determination of kinetics parameters

by isoconversional method

Kinetics parameters vary with extent of conversion at the multi-step kinetics, such as dehydration of CSH. Isoconversional methods employ multiple heating rates in order to obtain data on varying rates at a constant extent of conversion. Thus, isoconversional methods allow multi-step processes to be detected via a variation of $E_{\mathrm{a}}$ with $\alpha$. The dehydration degree is calculated from TG curves first: 
Fig. 1 Separation of TG curve of cement paste into TG curves of $\mathrm{CSH}$ and $\mathrm{CH}$

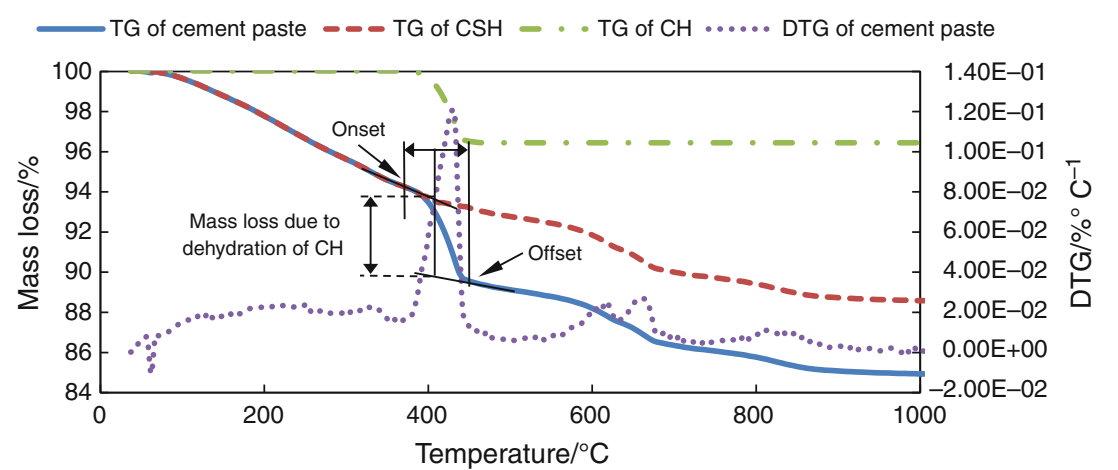

$\alpha=\frac{w_{\mathrm{i}}-w_{0}}{w_{\text {final }}-w_{0}}$

where $w_{i}$ is the mass during dehydration, $w_{0}$ is the initial mass, $w_{\text {final }}$ is the final mass after dehydration. In this study, isoconversional Friedman method was performed [10], and the reaction order is assumed to be one:

$\ln \left(\frac{\mathrm{d} \alpha}{\mathrm{d} t}\right)=-\frac{E_{\mathrm{a}}}{R T}+\ln A+\ln (1-\alpha)$

by plotting $\ln (\mathrm{d} \alpha / \mathrm{d} t)$ against $1 / \mathrm{T}$, one directly obtains the slope $-E_{\mathrm{a}} / \mathrm{R}$ for a fixed $\alpha$. And the $\ln A$ can be determined by the intercept $\ln A+\ln (1-\alpha)$.

\section{Results and discussion}

The XRD pattern of dried Portland cement paste is shown in Fig. 2. The crystalline phases are determined. Alite, belite, quartz and brownmillerite are ingredients of unhydrated clinker. Portlandite $(\mathrm{CH})$ is the hydration product. Due to amorphous structure of $\mathrm{CSH}$, the peaks of $\mathrm{CSH}$ gel can't be found in the XRD pattern. Because the samples are isolated with air during curing, the calcite $\left(\mathrm{CaCO}_{3}\right)$ is not detected in the samples. Therefore, decarbonation of samples during heating is neglected.

The mass loss curves of samples under different heating rates were shown in Fig. 3a. A rapid mass loss at around $450^{\circ} \mathrm{C}$ was observed in each TG curve, that was caused by dehydration of $\mathrm{CH}$. By using the graphic method in Section
"Separation of TG curve", the mass loss curves of $\mathrm{CH}$ and $\mathrm{CSH}$ at different heating rate are determined subsequently in Fig. 3b, c. Both dehydration of $\mathrm{CH}$ and $\mathrm{CSH}$ were significantly affected by the heating rate, which are shown in Fig. 3b, c. In these figures, it was found that at the same temperature the dehydration degree of the sample with low heating rate is larger than that of the sample with high heating rate. This is because the sample with lower heating rate has more time to dehydrate.

It was also found that the temperature range corresponding to the dehydration of $\mathrm{CH}$ varies with the heating rate (Fig. 3c). For the samples with different heating rate, the dehydration starts at the same temperature, but ends at different temperature. This is because the samples with higher heating rate need less time to reach target temperature, and its dehydration time is less.

The curves of $\ln (\mathrm{d} \alpha / \mathrm{d} t)$ against $1 / \mathrm{T}$ of $\mathrm{CSH}$ and $\mathrm{CH}$ at fixed dehydration degrees range from 0.1 to 0.9 were plotted and showed in Fig. 4. It was observed that the plots of $\ln (\mathrm{d} \alpha / \mathrm{d} t)$ against $1 / \mathrm{T}$ of $\mathrm{CSH}$ and $\mathrm{CH}$ were linear. The trend of $\ln (\mathrm{d} \alpha / \mathrm{d} t)$ against $1 / \mathrm{T}$ plots of $\mathrm{CSH}$ varies with dehydration degree (Fig. 4a). In the contrast, all $\ln (\mathrm{d} \alpha / \mathrm{d} t)$ against $1 / \mathrm{T}$ plots of $\mathrm{CH}$ at different dehydration degrees overlap together (Fig. 4b).

By making trend lines of the $\ln (\mathrm{d} \alpha / \mathrm{d} t)$ against $1 / \mathrm{T}$ plots in Fig. 4, the $E_{\mathrm{a}}$ and $\ln A$ are determined and showed in Fig. 5. It is showed that the $E_{\mathrm{a}}$ and the $\ln A$ of CSH develop with $\alpha$ obviously. And the the $E_{\mathrm{a}}$ and the $\ln A$ of $\mathrm{CH}$ almost keep the same during the dehydration process. The average $E_{\mathrm{a}}$ of dehydration of $\mathrm{CH}$ is $151.82 \mathrm{~kJ} / \mathrm{mol}$.
Fig. 2 XRD pattern of dried Portland cement paste (oven dried by $105^{\circ} \mathrm{C}$ )

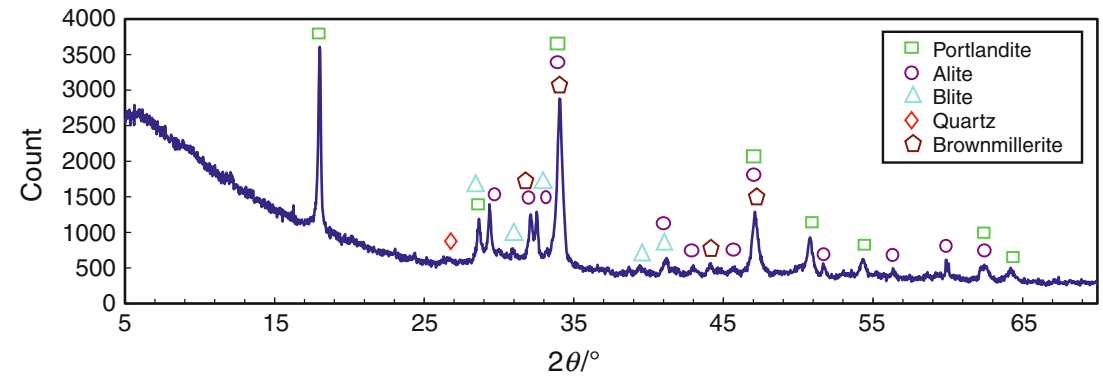


Fig. 3 TG curves of cement paste, $\mathrm{CSH}$ and $\mathrm{CH}$

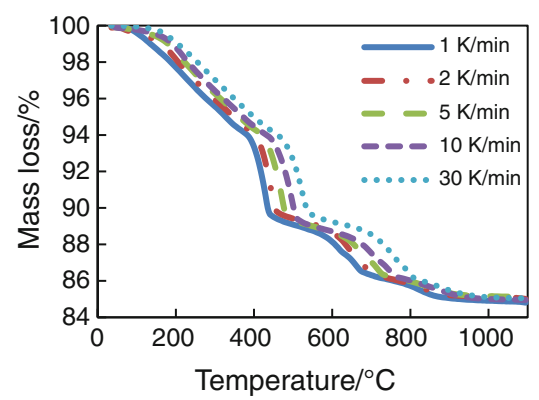

(a) Cement paste

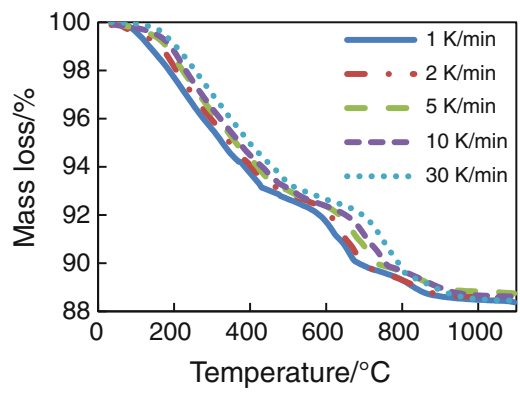

(b) $\mathrm{CSH}$

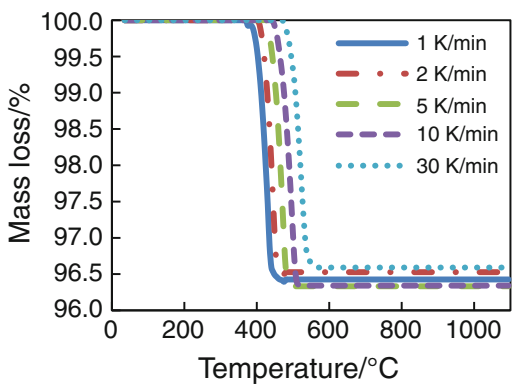

(c) $\mathrm{CH}$

Fig. 4 Plots of $\ln (\mathrm{d} \alpha / \mathrm{d} t)$ against $1 / \mathrm{T}$ of $\mathrm{CSH}$ and $\mathrm{CH}$
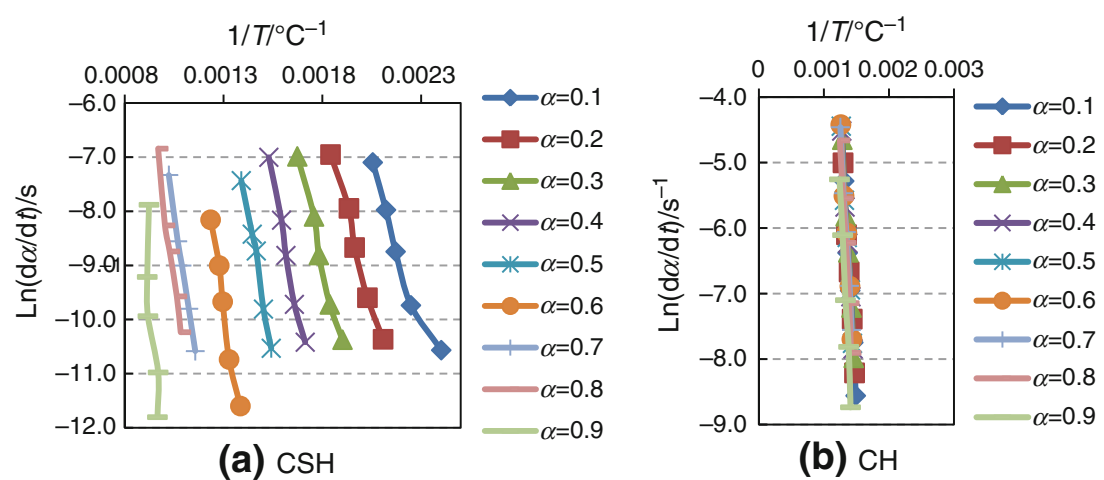

(b) $\mathrm{CH}$
Fig. 5 Activation energy and $\ln A$ determined by isoconversional method

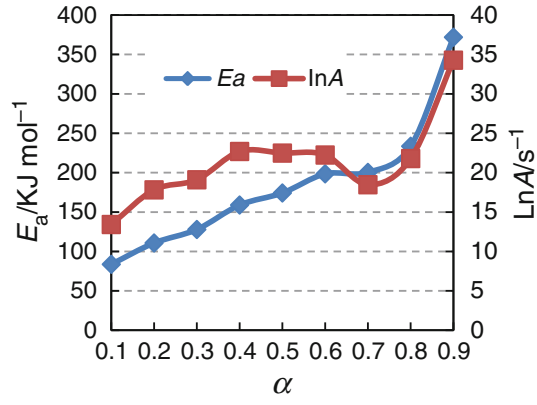

(a) $\mathrm{CSH}$

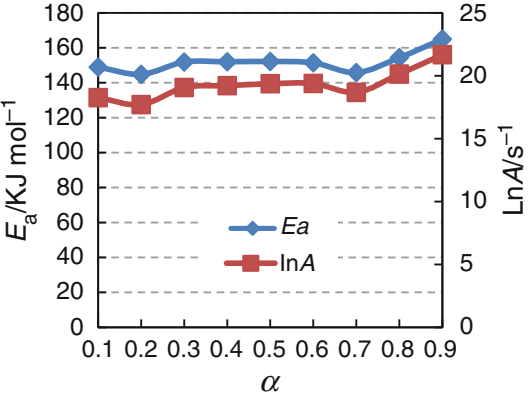

(b) $\mathrm{CH}$
Discussion on variation of $E_{\mathrm{a}}$ with progress of reaction

The activation energy $E_{\mathrm{a}}$ is the average excess energy that a water molecule must possess to release [11]. A variation of $E_{\mathrm{a}}$ with reaction process implies that systematic change of reactivity takes place during the progress of a reaction. The possible reasons of a variation of $E_{\mathrm{a}}$ were discussed by Galwey [12].

The variation of $E_{\mathrm{a}}$ of $\mathrm{CH}$ with $\alpha$ is very small (relative standard deviation $=3.85 \%$ ). This can be explained that 
the dehydration of $\mathrm{CH}$ is a single step reaction. During the reaction process, the energy barrier to bond redistribution of $\mathrm{CH}$ almost keep the same. The small variation of $E_{\mathrm{a}}$ might be caused by computational error.

The large variation of $E_{\mathrm{a}}$ of $\mathrm{CSH}$ with $\alpha$ can be explained by that the dehydration of $\mathrm{CSH}$ is a multistep reaction. The CSH gel in hydrated cement paste has consists of many small globules with a disordered layered structure [13]. There are some water molecules absorbed in the interlayer space and surrounding globule (Fig. 6). Because of the complexity of gel structure, different water molecules requires different energy to be released. At high temperature, the monolayer water molecules that surrounds globule are released first, when the interlayer water molecules keep the same. When temperature is sufficiently high, the interlayer water molecules are released finally. Moreover, the CSH structure varies with temperature rising. As Taylor [7] pointed out, the interlayer spacing shrunk with release of water molecule. The smaller the spacing between $\mathrm{CSH}$ layer is, the more energy could be required to dehydrate.

\section{Verification}

In order to verify the measured kinetics parameters, the above kinetics model is compared with further experimental data. The above kinetics parameters are computed from the data under different heating rate. But in principle, they are intrinsic parameters, which are applicable for the case under any temperature profile. If an arbitrary temperature-time relation is given, the total mass loss of cement paste at any time can be calculated. The dehydration degrees of $\mathrm{CSH}$ and $\mathrm{CH}$ can be calculated by numerical method first. The numerical forms of dehydration degree of $\mathrm{CH}$ and $\mathrm{CSH}$ are showed as following:

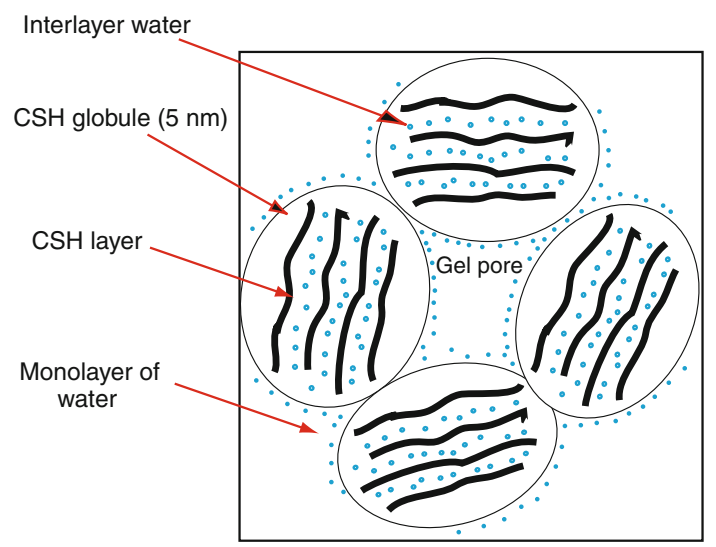

Fig. 6 A schematic of globulous structure of $\mathrm{CSH}$ gel $\alpha_{i+1, \mathrm{CSH}}=\alpha_{i, \mathrm{CSH}}+\left(1-\alpha_{i, \mathrm{CSH}}\right)^{n} A_{0, i, \mathrm{CSH}} \exp \left(-E_{a, i, \mathrm{CSH}} / R T_{i}\right) \Delta t$

$\alpha_{i+1, \mathrm{CH}}=\alpha_{i, \mathrm{CH}}+\left(1-\alpha_{i, \mathrm{CH}}\right)^{n} A_{0, \mathrm{CH}} \exp \left(-E_{\mathrm{a}, \mathrm{CH}} / R T_{i}\right) \Delta t$

where $t$ is time, $i$ is the time step, $\Delta \mathrm{t}$ is the time step length. Combining the dehydration of $\mathrm{CSH}$ and $\mathrm{CH}$, the mass loss in the total dehydration process of cement paste can be characterized as following:

$W_{\text {cem }}=W_{\mathrm{CSH}} \alpha_{\mathrm{CSH}}+W_{\mathrm{CH}} \alpha_{\mathrm{CH}}$

where $W_{\text {cem }}$ is the total mass loss of cement paste, $W_{\mathrm{CSH}}$ is the maximum mass loss caused by dehydration of $\mathrm{CSH}$, $W_{\mathrm{CH}}$ is the maximum mass loss caused by dehydration of $\mathrm{CH}$.

To validate both the kinetics of isothermal and nonisothermal process, the cement paste was heated under a multi-segment temperature program. The sample was heated with rate $5^{\circ} \mathrm{C} / \mathrm{min}$ first. When temperature reached $200^{\circ} \mathrm{C}$, the temperature programmer was switched from dynamic heating mode to the isothermal condition for $60 \mathrm{~min}$. At the end of the $60 \mathrm{~min}$, the temperature programmer was switched again to dynamic heating until $400^{\circ} \mathrm{C}$. Then the sample was kept in $400^{\circ} \mathrm{C}$ for another $60 \mathrm{~min}$. At the end of the isothermal process, the sample was heated again with heating rate $15^{\circ} \mathrm{C} / \mathrm{min}$ until $1,000^{\circ} \mathrm{C}$. Figure 7 illustrated that the simulated results agreed with the experimental data very well not only in non-isothermal segments but also in isothermal segments. When the heating method was switched from dynamics heating mode to the isothermal condition, the equilibrium state of $\mathrm{CSH}$ was not reached immediately. Therefore, the dehydration reaction proceeded at both isothermal segments and nonisothermal segments. Because the activation energy increased along with extent of dehydration, the reaction rate decreased gradually in the isothermal segment.

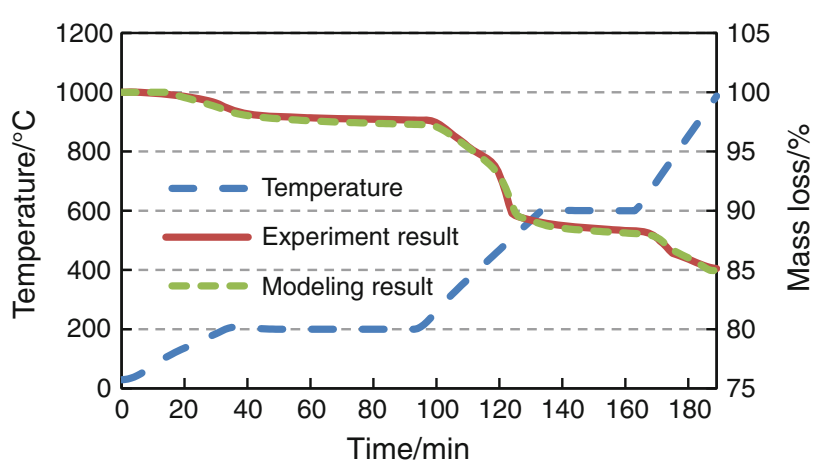

Fig. 7 Comparison of mass loss measured by thermogravimetry and mass loss curve predicted by kinetics model under complex temperature program 


\section{Conclusions}

In order to characterize the kinetics of the dehydration of different phase in cement paste, a global kinetics of cement paste was considered as the combination of kinetics of $\mathrm{CSH}$ and $\mathrm{CH}$. The phases in cement paste was identified by powder XRD. Isoconversional methods [8, 10] were performed to study the dehydration kinetics of $\mathrm{CSH}$ and $\mathrm{CH}$. The $E_{\mathrm{a}}$ and the $\ln A$ of the dehydration of $\mathrm{CSH}$ and $\mathrm{CH}$ were determined, respectively. The following conclusions can be drawn:

- In the fresh Portland cement paste that has been oven dried at $105^{\circ} \mathrm{C}, \mathrm{CSH}$ and $\mathrm{CH}$ are the main hydration products. The minor crystalline phase (like $\mathrm{CaCO}_{3}$ ) can be neglected during the dehydration.

- The $E_{\mathrm{a}}$ of the dehydration of $\mathrm{CH}$ is about $151.82 \mathrm{~kJ} /$ mol. The variation of $E_{\mathrm{a}}$ of the dehydration of $\mathrm{CH}$ is very small.

- The $E_{\mathrm{a}}$ of the dehydration of CSH varies from 83.69 to $371.93 \mathrm{~kJ} / \mathrm{mol}$. The variation of $E_{\mathrm{a}}$ of the dehydration of CSH is explained by its complex globulous structure at high temperature.

- The global kinetics model of cement paste and its measured parameters were verified by comparing the simulated mass loss with experimental data.

Acknowledgements The authors thank the Dutch National Science Foundation (STW) for financially supporting the research project on "Explosive spalling of concrete: towards a model for fire resistant design of concrete elements" (code no. 07045).

Open Access This article is distributed under the terms of the Creative Commons Attribution License which permits any use, distribution, and reproduction in any medium, provided the original author(s) and the source are credited.

\section{References}

1. Khoury GA, Majorana CE, Pesavento F, Schrefler BA. Modelling of heated concrete. Mag Concr Res. 2002;54(2):77-101.

2. Shaw S, Henderson CMB, Komanschek BU. Dehydration/ recrystallization mechanisms, energetics, and kinetics of hydrated calcium silicate minerals: an in situ TGA/DSC and synchrotron radiation SAXS/WAXS study. Chem Geol. 2000;167(1-2): 141-159.

3. Alonso C, Fernandez L. Dehydration and rehydration processes of cement paste exposed to high temperature environments. J Mater Sci. 2004;39(9):3015-3024.

4. Alarcon-Ruiz L, Platret G, Massieu E, Ehrlacher A. The use of thermal analysis in assessing the effect of temperature on a cement paste. Cem Concr Res. 2005;35(3):609-613.

5. Bazant ZP, Kaplan MF. Concrete at high temperatures: material properties and mathematical models. London: Longman; 1996.

6. Taylor HFW. The water content of calcium sillicate hydrate(I); 1953.

7. Taylor HFW. The dehydration of tobermorite. In: clays and clay minerals, 6th Nat. Conf. Pergamon Press: New York; 1959. p. 101-109.

8. Vyazovkin S, Sbirrazzuoli N. Isoconversional kinetic analysis of thermally stimulated processes in polymers. Macromol Rapid Commun. 2006;27(18):1515-1532.

9. Friedman HL. Kinetics of thermal degradation of char-forming plastics from thermogravimetry: application to a phenolic plastic. J Polym Sci Part C Polym Symp. 1964;6(1):183-195.

10. Brown ME, Maciejewski M, Vyazovkin S, Nomen R, Sempere J, Burnham A, et al. Computational aspects of kinetic analysis: part A: the ICTAC kinetics project-data, methods and results. Therm Acta. 2000;355(1-2):125-143.

11. Galwey AK, LinkBrown ME. Thermal decomposition of ionic solids. Elsevier: Amsterdam; 1999.

12. Galwey AK. What is meant by the term variable activation energy when applied in the kinetic analyses of solid state decompositions (crystolysis reactions)? Therm Acta. 2003;397 (1-2):249-268.

13. Jennings HM. Refinements to colloid model of $\mathrm{C}-\mathrm{S}-\mathrm{H}$ in cement: CM-II. Cem Concr Res. 2008;38(3):275-289. 